\title{
Placental Accretism before 20 Weeks of Gestational
} Age

\author{
Ricardo Illia* \\ Department of Obstetrics, Buenos Aires University, Argentina
}

Submission: March 06, 2017 ; Published: March 20, 2017

*Corresponding author: Ricardo Illia, Department of Obstetrics, Buenos Aires University, Fellow ACOG Buenos Aires Argentine Section, Chief of Obstetrics Service, Hospital Alemán, Buenos Aires, Argentina, Email: rhillia@gmail.com

\section{Introduction}

Defined as placental accretism, is the abnormal partial or total adherence of the placenta to the underlying uterine surface [1]. It is little common to find this anomaly in the first half of pregnancy.

In more advanced pregnancies, Miller et al. [2] report that the placental accretism occurred in $9.3 \%$ of patients with placenta previa versus $0.004 \%$ in patients without previous placenta (RR 2.065, P<0.0001). Between patients with placenta previa, accretism risk was increased in patients over 35 years and with a history of previous c-sections. Is interesting to take in consideration the reflections of Chau et al about the cytoquines role in the placental advance into the myometrium.

In terms of the accretism in the first half of the pregnancy, the posted information is scarce and only on isolated cases.

Wheeler et al. [3] report a case diagnosed by ultrasound at 18 week's of gestation, that ended in a total hysterectomy before fetal viability.

Arredondo et al. [1] reported a case of accretism in first trimester requiring total hysterectomy for resolution at this stage of pregnancy. This patient presented as risk factor associated with a history of three uterine curettages to end early pregnancies.

Bernal \& cols [4] in a patient of 19 weeks of gestational age with signs of acute abdomen, performed a laparotomy, finding an uterine rupture with placental percretismo requiring total hysterectomy.

Kinoshita et al. [5] report a case of placental percretism which arose as an acute abdomen at 25 week's of gestational age, which required a total hysterectomy with diagnostic presumption through pathology confirmation for this treatment. This patient had no history neither previous pregnancies nor operations in the womb. Mueller et al. [6] reported a case of similar developments at 18 weeks pregnancy but the attributable cause of spontaneous uterine rupture was an adenomyosis.
Monks et al. [7] reported a case of cervical pregnancy with associated placental percretism, both diagnoses were performed successfully by ultrasonography and analyzed conservative or aggressive therapeutic possibilities according to the general condition of the patient.

Slomko et al. [8] presented a case of placental percretism during abdominal caesarean section, and pose considered therapeutic alternative to resection of the myometrium committed to the further metroplastia.

Durand Reville et al. [9] report that the diagnosis of placental accretism and percretism can be done by ultrasound B-mode and Doppler color. The extension of placenta very vascularized to the myometrium, complex placenta-subplacenta abnormal and flow vascular through the myometrium suggest the diagnosis. In the present times, is common to add magnetic [10].

resonance to help to make the diagnosis of accretism, but some authors said that is not neccesary because ultrasound is enough [11-13].

As mentioned at the beginning of the review, information on anomalies of placentation in early stages of pregnancy is rare and isolated, presenting a history of risk caesarean section and uterine curettages or in some case even without a history of risk. Also we have to take in consideration the gynecological procedures into the uterus such as hysteroscopy and myiomectomies.

Then we will present four cases of accretism or placental percretism in pregnancies of less than 20 weeks of gestational age.

\section{Case 1}

30 year-old patient who consults with menstrual delay of 6 weeks, positive gonadotrophin, with a history of two previous c-sections. It begins with little genital bleeding so is medicated with progesterone and rest. The bleeding does not generate any associated pain, motive by wich it was performed an ultrasound that shows gestational sac normoimplanted without embryo. A 
new ultrasound reports egg without embryo so it was decided expectant management given the reduced size of the gestational sac $(30 \mathrm{~mm})$. The patient will not cameto office for about 6 weeks, period after which consultation again referring absence of bleeding but either not had menses.

The gynecological examination presents soft uterus, increased in size as 3 months of pregnancy.Evacuator curettage is scheduled. During the surgical act, the feeling on the curette is of consistency soft and soon after starting curettage the uterus started to bleed with a metrorrhagia each time more intense, that not reversed with oxytocic. This picture is of such intensity that despite blood transfusions undertaken the general condition of the patient was impaired. It was decided to carry out exploratory laparotomy and observed uterus in barrel with bluish appearance, soft consistency. A total hysterectomy is performed and the patient evolved favorably. The pathology report, reveals placental accretism.

\section{Case 2}

43 year-old patient who consults with 7 week's pregnancy. Obstetric history has two previous c-sections (the last 18 years ago). Started with threatened abortion and at consultation presents abortion in progress with removal of remains for external cervical OS. Described evacuator curettage which is initially carried out without problems, but a bit of starting the procedure occurs unenforceable metrorrhagia of red blood, to then see absence of ability to coagulate. In the absence of systemic manifestations of coagulopathy and the profuse of metrorrhagia with severe compromise of the general condition of the patient it was decided to practice a total hysterectomy with resolution picture and recovery of the general condition of the patient after two days of hospitalization in intensive care unit. The pathology of the surgical specimen reported placenta accreta.

\section{Case 3}

Patient 43-year-old with a history of two previous c-sections, the last 9 years ago. With pregnancy confirmed by beta HCG (60 U) 7 weeks, is presented to the consultation with abundant bleeding of red blood. Ultrasound evaluation reports uterus $106 \mathrm{~mm} \times 36 \mathrm{~mm} \times 49 \mathrm{~mm}$ with deformation before the istmic-body showing ecoestructural alteration with solid area and more liquid which altogether measure $48 \times 17 \times 34 \mathrm{~mm}$. Image is under the previous caesarean section scar and at that level the echo endometrium-cavitary is identified. In addition liquid area shows a strong wall image of $9 \mathrm{~mm}$.

Faced with this situation, with the firm suspected of trophoblast invading the myometrium and the risk of producing a solution of continuity if we perform a curettage, the Departmentat debate considered convenient to try to inactivate the trophoblast administrating methotrexate, which was administered at a dose of $50 \mathrm{mg} / \mathrm{kg}$. After 24 hours of drug administration the patient presents to the ultrasound examination a $42 \times 21 \times 28 \times m m$ with $10 \mathrm{~mm}$ embryo sac. At $48 \mathrm{hr}$ the ultrasound report was similar and the patient receives the transient discharge from hospital. After 48 hours of discharge, the ultrasound image shows sac with multiple internal echoes and beta HCG value was $30 \mathrm{u}$. with patient asymptomatic. The last ultrasound showed an image of $24 \times 20 \times 21 \mathrm{~mm}$ on the scar with beta HCG negative. After 30 days, the patient is asymptomatic with normal gynecologic ultrasound and beta HCG still negative.

\section{Case 4}

Patient of 38 years with a history of a previous c-section and 3 uterine curettages to evacuate stopped pregnancies. At booking, the patient continued with persistent and continuous bleeding from two months ago, when it was performed a curettage because stopped pregnancy. It is admitted in the obstetrics service for study and evaluation. The beta in blood was low positive $(300 \mathrm{mu} / \mathrm{ml})$. Study ultrasound, in principle showed images compatible with trophoblastic disease. He was tried in principle the uterine evacuation using vaginal and oral misoprostol without success, so it was decided to perform an intrauterine aspiration for evacuation of its content.

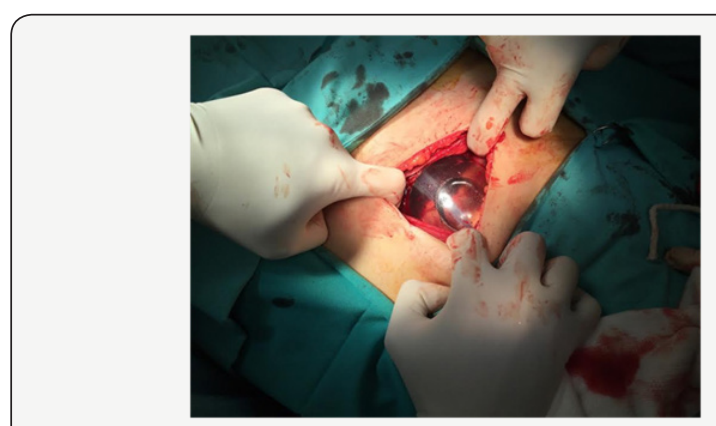

Figure 1: At the beginning of surgery, it was observed the Bakri balloon free into the abdominal cavity, induced us to think that the bleeding stopped because the balloon put the uterus against the sacral bone.

Under general anesthesia the procedure begins, and immediately started, the patient begins with intense bleeding that does not respond neither to drugs to contract the uterus and stop bleeding nor curettage of the uterine cavity. With hemodynamically compromised patient, decides the placement of a of Bakri balloon, stopping bleeding with filling with 500cc saline. Because the bleeding, maneuvers were suspended until improvement of the general condition of the patient who was sent to intensive care unit for recovery. To the $24 \mathrm{hs}$ of evolution, with the patient hemodynamically stable, was observed by ultrasound and magnetic resonance that the balloon was free in the pelvis, outside of the uterus. This allows to deduce that hemostasis was accomplished by compression of the uterus against the sacrum when the balloon was filled. In front of this situation, it was decided an exploratory laparotomy. Open peritoneum, hemoperitoneum and the balloon in cavity (Figure 1) is observed. Withdraws it, noting the uterus with clear signs of trophoblastic invasion. We decided to make a total hysterectomy to resolve the problem that was accomplished with success (Figure 2). Hysterectomy piece clearly showed a placental 
percretism with mild commitment of the bladder which was dissected and liberated to be able to remove the uterus (Figure 3). The patient was in perfect state and she was discharged $96 \mathrm{hrs}$ of postoperative evolution (Figure 4).

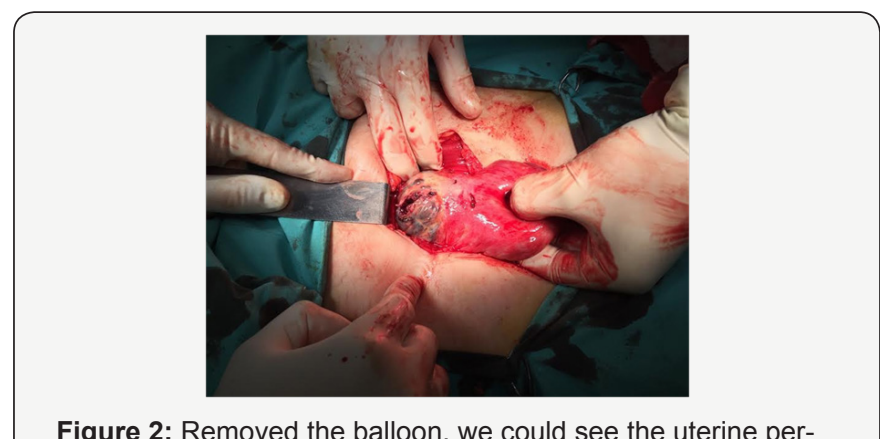

Figure 2: Removed the balloon, we could see the uterine percretism at the uterine istmus with a little bladder compromise.
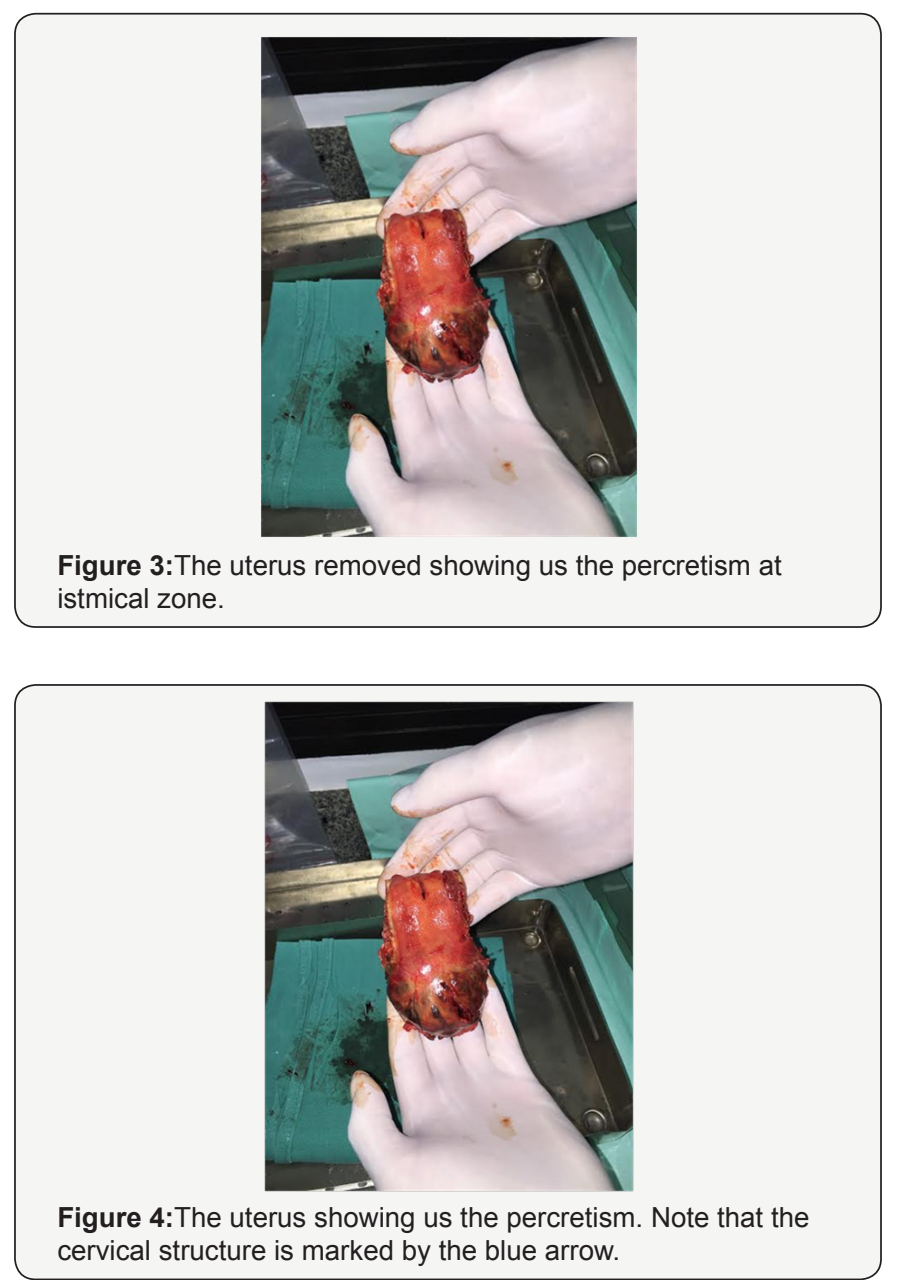

\section{Discussion}

Apparently we have a very rare entity as revealed by the literature search,but able to act with an unusual gravity still in early stages of gestation, with pictures of profuse bleeding which seriously compromise the health of the patient and whose most frequent solution is thetotal hysterectomy. Mostly these patients presented the factors of risk set forth by Miller \& cols [2]: maternal age over 35 years and history of Caesarean sections and curettages in the past.

Up to the present time, these factors were taken into account as at risk for placental accretism in more mature pregnancies, since the accretism is increasingly common in direct relation to the increase in the incidence of caesarean sections.

But the cases presented, together with the cases presented in the literature [1-8] describes a serious clinical picture, low frequency but high severity, in less than 20 weeks pregnancy. Some professionals adopt behaviors expectantly before diagnoses of detained pregnancies or anembryonic eggs on the idea of obtaining full or partial spontaneous evacuation to avoid traumatic cervical dilatation with Hegar dilators which could produce a subsequent cervical incompetence. Of agreement to these observations, this behavior in the event that the patient as a history of caesarean or have 35 or more years, you can keep this way of following of the patient, but with close ultrasound control to allow the opportunity to diagnose a possible placental accretism.

If the patient is with profuse bleeding, treatment generally is total hysterectomy since bleeding is by direct vascular lesion produced by the trophoblast in its myometrial invasion. In the case of a placental accretism is suspected, treatment with methotrexate is a valid alternative to try to avoid a surgical treatment at first instance, but in the case of heavy bleeding, the only treatment is the hysterectomy, because is weird that embolization treatments should be successful in front of such amount of bleeding. The administration of one or more series of methotrexate dose of $50 \mathrm{mg} / \mathrm{kg}$ of weight via paraenteral with an ultrasound monitoring and quantification of beta HCG is presented as a possibility to avoid radical surgical treatments in pathology from the first half of pregnancy.

\section{References}

1. Arredondo-Soberón F, Sabella V, Garza-Leal J, Valente PT (1995) Placenta accreta during the first trimester of pregnancy. A case report. Ginecol Obstet Mex 63: 279-281.

2. Miller J, Chollet T, Goodwin TM (1997) Clinical risk factors for placenta previa-placenta accreta. Am J Obstet Gynecol 177(1): 210-214.

3. Wheeler T, Anderson T, Kelly J, Boehm FH (1996) The Placenta increta diagnosed at 18 weeks' gestation. Report of a case with sonographic and pathologic correlation. J Reprod Med 41(3): 198-200.

4. Martínez BS, Chavez H, Villa F (1996) Uterine rupture and placenta percreta in the second trimester. Presentation of a case. Ginecol Obstet Mex 64: 482-483.

5. Kinoshita T, Ogawa K, Yasumizu T, Kato J (1996) The Spontaneus rupture of the uterus due to placenta percreta at 25 weeks' gestation:a case report. J Obstet Gynaecol Res 22(2): 125-128.

6. Mueller M, Brühwiler G, Saile H (1996) Spontaneous uterine rupture in the 18th week of pregnancy in a patient with adenomyosis primigravida. Zentralbl Gynakol 118(1): 42-44. 
7. Monks P, Catalano, Close P (1993) Acase report: cervical pregnancy with placenta percreta an ultrasonic assisted diagnosis. Asia Oceania J Obstet Gynaecol 19(1): 37-41.

8. Slomko Z, Kedzia H, Friebe Z (1994) Partial excision of the anterior uterine wall for placenta accreta. Ginekol Pol 65(6): 326-330.

9. Durand-Réville M, Robert Y, Dufour P, Lucot JP, Rocourt N (1997) Ultrasonic diagnosis of placenta percreta. Apropos of a case with hemorrhagic complication. J Radiol 78(4): 313-316.

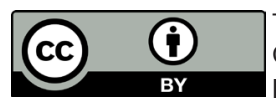

This work is licensed under Creative Commons Attribution 4.0 Licens

DOI: 10.19080/JGWH.2017.03.555609
10. Chau A, Markley JC, Juang J, Tsen LC (2016) Cytokines in the perinata period-Part I International Journal of Obstetric Anesthesia 26: 48-58.

11. Perez-Delboy A, Wright JD (2014) Surgical management of placenta accreta: to leave or remove the placenta? BJOG 121(2): 163-170.

12. Eller AG, Porter TF, Soisson P, Silver RM (2009) Optimal management strategies for placenta accreta. BJOG 116(5): 648-654.

13. Belfort MA (2010) Placenta accreta. Am J Obstet Gynecol 203(5): 430439

\section{Your next submission with Juniper Publishers will reach you the below assets}

- Quality Editorial service

- Swift Peer Review

- Reprints availability

- E-prints Service

- Manuscript Podcast for convenient understanding

- Global attainment for your research

- Manuscript accessibility in different formats ( Pdf, E-pub, Full Text, Audio)

- Unceasing customer service

Track the below URL for one-step submission https://juniperpublishers.com/online-submission.php 